\title{
The Story of Chinese Characters (0031-0040) When Translated on Korean Pronunciation
}

\author{
Hyeonhi Regina Park1, Kunjoo Daegon-Andrea Kim², Jiah Anna Kim³, Rosa Kim4, Alain Hamon5, Sohwa \\ Therese Kim${ }^{6}$, Sangdeog Augustin $\mathrm{Kim}^{7^{\star}}$ \\ 1Department of Elderly care and welfare, Joongbu University, Kumsan, Republic of Korea ROK, \\ 2Department of History, Yonsei University, Seoul, and ROK, \\ 3Department d'Expertise economique, Universite de Paris-Est Creteil, Paris, France, \\ ${ }^{4}$ Specialite d'Economie politique, Ecole des Hautes Etudes en Sciences Sociales(EHESS), Paris, France \\ 5L'Ecole Internationale Jean-Mermoz, Abidjan, Cote d'Ivoire, \\ ${ }^{6}$ Department of French language and literature, Seoul Women's University, Seoul, ROK, \\ ${ }^{7}$ Department of Companion animal and animal resources science, Joongbu University, Kumsan, ROK \\ *Corresponding Author \\ Sangdeog Augustin Kim
}

\section{Article History}

Received: 17.10 .2019

Accepted: 24.10 .2019

Published: 30.10 .2019

\begin{abstract}
The researchers have tried to pronounce the part of the letter, and then investigate if there is some meaning of the part of the letter when assembled together on a Korean pronunciation method. Because the researchers have obtained the similar results as shown on the analysis of Tcheonzamun (The thousand character essay). We analyzed the Chinese characters with the method of using Korean pronunciation. We translated the 10 Chinese characters randomly, and named them the continuous number of 0031 to 0040. As a conclusion the researchers have found the ancient Korean people's sense and frankness shown on Chinese characters. And it is known that the meaning through Korean pronunciation is more expressive than the present meaning.
\end{abstract}

Keywords: Chinese characters, Korean pronunciation, Tcheonzamun (The thousand character essay), continuous number of 0031 to 0040 of Chinese characters, Korean people's sense and frankness.

\section{INTRODUCTION}

It is well known that the origin of Chinese characters is the Chinese people and that those letters were in long history used as the basic foundation of the culture in East Asia. Such countries as China itself, Korea, Japan, Vietnam, et cetera, are included. However, the meaning of the character was not well recognized until now. And Dallet[1] suggested that there are several distinct differences between China and Korea. Therefore, the present researchers tried to find the meaning in a different method [2]. The method is to separate the Chinese character. Then, the researchers have tried to pronounce the part of the letter, and then investigate if there is some meaning of the part of the letter on a Korean pronunciation method. Because the researchers have obtained the similar results on the analysis of Tcheonzamun (The thousand character essay) [2, 3].

\section{Materials ANd Methods}

The present researchers analyzed the Chinese characters with the method of using Korean pronunciation. The researchers translated the 10 Chinese characters randomly, and named them the continuous number of 0031 to 0040 . The method is to separate the Chinese character. Then, the researchers have tried to pronounce the part of the letter, and then investigate if there is some meaning of the part of the letter on a Korean pronunciation method.

Copyright @ 2019: This is an open-access article distributed under the terms of the Creative Commons Attribution license which permits unrestricted use, distribution, and reproduction in any medium for non commercial use (NonCommercial, or CC-BY-NC) provided the original author and source are credited. 


\section{RESULTS AND DISCUSSION}

The method is to separate the Chinese character. Then, the researchers have tried to pronounce the part of the letter, and then investigate when assembled together if there is some meaning of the part of the letter on a Korean pronunciation method. character

Number, Pronunciation of the Chinese character (Chinese character): Meaning in Korean pronunciation of the Chinese

0031 An (安): “Ye!” Hamyeon

"If I say(一; Ha) (`; myeon) 'Yes!'(X; Ye!)" or "If you say 'Yes!" (the original meaning).

'It is comfortable.' (The present meaning).

$0032 \mathrm{Ga}$ (家): Byeol Ddong Maneul Deopgo

"We only (勿; Man) (一; eul) have, as blanket( $\neg$; Deop) ( I ; go), falling star( ) ; Byeol) ( ' ;

Ddong) which drops instantly from heaven." (the original meaning).

"It is the house." (The present meaning).

$0033 \mathrm{Sa}$ (思): "Keuyeot Kuman!"

"It is the very man (the very woman)( ; Keu) that I always miss!(十; yeot) ( I ; Ku) (心;man!)" (the original meaning).

"I think." (The present meaning).

0034 Hyang (香): "Sikeum Hasi!"

"Oh it is very sour! So I cannot eat this food!" (The original meaning).

When a flower gives us fragrance, we say "It is good to smell!" (The present meaning).

Here there is difference between the original meaning and the present meaning.

0035 Song (松):

1) "Han Keun Byeol Zuryeona!"

"Will a great star (一; Han) ( I ; Keun) ( $)$; Byeol) be given to us! ( $;$ Zu) (八; ryeo) (ム;na!)" (The original meaning)

'It is a pine tree.' (The present meaning).

2) Goi Pago

"I will plant very preciously the tree on the soil. (the original meaning).

'It is the pine tree, and the tree is widely shown in Korea.' (The present meaning).

0036 Sil (室):

\section{1) "Deusina Hamyeon!)"}

"I strongly hope that he (she) would come here! When he (she) comes, I will accept him (her) in a truly joyful mode! ( - - ; Deu) ( I ;

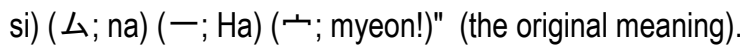

'It is a room' (the present meaning).

\section{2) Dul Sinna Hamyeon!}

Two people (- -; Dul), the wife and the husband, are joyful( I ; Sin) ( $\triangle$; na) $(-; \mathrm{Ha})(\sim$; myeon!) in their house! (The original meaning).

'It is a room' (the present meaning).

0037 Un (運): Deumbbuk Sa Meogge

"I want to buy(人; Sa) and eat( $\neg$; Meog)(車; ge) a lot of( 乡; Deum)(ト; bbuk) food!" (the original meaning). 
'Move.' (the present meaning).

0038 Sang(相):

1) Samkyeop Mag

"It is three-fold((三; Sam)(П; kyeop) membrane(木; Mag)." (the original meaning).

'Each other.' (the present meaning).

\section{2) Hagopa Keusae}

"I want to see you again in order to do something (一; Ha)( I ; go)(八; pa) newly with you! Even though I have just seen you! ( $\mathrm{Keu})($ 三; sae)!" (the original meaning).

'Each other.' (The present meaning).

\section{Tchag(着): Bul Byeol Samgo Neusse}

"Let's arrive lately (久; Neus)(三; se), we must do so with fire( 、 ; Bul) as the star( I ; Byeol)(三; Sam)( I ; go). Now it is very difficult for us to find the road to the destination! But let us continue to do this walk, and then at last we will reach our home!" (The original meaning). 'Arrive.' (The present meaning).

0040 Hon (昏): Sala Zuna!

"May I continue to live for you ( 1 ; Sal) (一; a) ( ‘ Zu) (日; na), my husband?" (the original meaning).

'Twilight.' (The present meaning).

As a conclusion the researchers have found the ancient Korean people's sense and frankness shown on Chinese characters. It is known that the meaning through Korean pronunciation is more expressive than the present meaning.

\section{ACKNOWLEDGEMENTS}

We thank Mr Ilsoo Joseph Kim and Mrs Bohwa Kim, Mr Yeonghag Park and Mrs Hilye Sarah Kim, Ms Jieun Agatha Kim. We thank Father Jean Blanc and Father Hifumi Iwazaki. We thank Mrs Tamako Hayashi and Mr Yoshihiro Hayashi, Mrs Francine Tenaillon and Professor Nicolas Tenaillon. We thank the students of Department of Companion Animal and Animal Resources Science in Joongbu University and the members of Daejeon Ludovich of Ordo Franciscanus Saecularis(OFS).

\section{REFERENCES}

1. Dallet, C.H. (1874). Histoire de l'Eglise de Coree (History of Korean Catholic Church). Victor Palme. Paris. France. 11-99.

2. Park, H.R.,Kim, J.A., Kim, K.D.A., Kim, J.A., Kim, S.T., Kim, R., Hamon, A., Kim, S.A.. (2017). Ancient Koreans petition to God in Tcheonzamun: The thousand character essay poem (641st to 656th letters). Journal of Languages and Culture, 8(6), 79-84.

3. Park, H.R., Kim, K.D.A., Kim, J.A., Kim, S.T., Kim, R., Hamon, A., Kim, S.A. (2019). The Story of Chinese Characters (00110020) When Translated On Korean Pronunciation. South Asian Res J Human Soc Sci, 1(3) (Oct-Nov, 2019): $209-211$. 